\title{
A Physis da Saúde Coletiva ${ }^{1}$
}

JOEL BIRMAN

A constituição da medicina científica na aurora do século XIX delineou a problemática da saúde nos registros individual e social. O saber médico configura-se, assim, como clínica ${ }^{3}$ e como prática médica ${ }^{4}$, discurso sobre o corpo singular e discurso sanitário sobre o espaço social. Com a emergência da sociedade industrial, a saúde das individualidades passa a incluir necessariamente as condições coletivas de salubridade, não sendo mais possível conceber a existência da saúde dos sujeitos na exterioridade das condições sanitárias do espaço social.

Nesse contexto, porém, o que se entende por saúde pública? O que se pretende dizer com a expressão "saúde coletiva"? Essas expressões constituem enunciados diversos do mesmo conceito e recobrem, portanto, um mesmo campo de práticas sociais? Ou, ao contrário, esses significantes denotam campos diferenciados, com superposições regionais e rupturas importantes? Indicações talvez inquietantes, já que temos naturalizada a idéia de saúde pública como sinônimo de saúde coletiva. Seus objetos teóricos seriam, portanto, idênticos.

Temos, no entanto, boas razões para pensar que essas expressões não se superpõem, principalmente se examinarmos a constituição das noções de saúde pública e saúde coletiva nos registros histórico e conceitual. Trata-se de campos não homogêneos, na medida em que se referem a diferentes modalidades de discurso, com fundamentos epistemológicos diversos e com origens históricas particulares.

O campo da Saúde Pública se constituiu com a medicina moderna no final do século XVIII, como polícia médica e com a medicina social, marcando o investimento político da medicina e a dimensão social das enfermidades. A 
saúde pública foi uma das responsáveis pela construção de uma nova estrutura urbana, pela produção de estratégias preventivas. Mas é inegável que seus diferentes discursos se fundam no naturalismo médico, que, invocando cientificidade, legitimou a crescente medicalização do espaço social. Combater as epidemias e as endemias, esquadrinhando o espaço urbano com dispositivos sanitários, constituiu-se como estratégia dominante da saúde pública. As razões do Estado, enfim, que tomou as condições de saúde de sua população como sua riqueza maior ${ }^{5}$, constituíram-se como o grande suporte para a construção dos dispositivos da saúde pública.

As epidemias representaram o campo privilegiado para a produção, reprodução e diversificação da medicalização do campo social, com o fortalecimento correlato do poder da medicina ${ }^{5}$. Entretanto, a caução científica do discurso naturalista da medicina sempre colocou entre parênteses a dimensão política das práticas sanitárias. A recente epidemia de AIDS revela mais uma vez esse processo, que se repete desde o século XIX no Ocidente: em nome do discurso da ciência, legitimam-se práticas de marginalização de diferentes segmentos sociais ${ }^{7}$.

As descobertas biológicas multiplicam o poder social da medicina, conferindo à perspectiva universalizante, presente no discurso naturalista, uma legitimidade que silencia qualquer consideração de ordem simbólica e histórica na leitura das condições das populações a que se destinam as práticas sanitárias. Nesta perspectiva, as descobertas bacteriológicas de Pasteur, que representaram um avanço fundamental no conhecimento biológico das infecções, contribuíram para apagar qualquer significação diferencial dos corpos, nos quais se realizaram as práticas de assepsia. A leitura naturalista se impôs como razão triunfante, legitimando com sua universalidade as práticas de medicalização. Enfim, a Saúde Pública encontrou definitivamente seu solo fundador na Biologia, perdendo assim qualquer medida que relativizasse seus dispositivos e que permitisse considerar a especificidade social das comunidades sobre as quais incide.

A concepção de Saúde Coletiva, bem ao contrário, se constituiu através da crítica sistemática do universalismo naturalista do saber médico. Seu postulado fundamental afirma que a problemática da saúde é mais abrangente e complexa que a leitura realizada pela medicina. A partir da década de 1920, as Ciências Humanas começaram a se introduzir no território da saúde e, de modo cada vez mais enfático, passaram a problematizar categorias como normal, anormal, patológico. Nelas haveria valores. Por isso, a instituição dessa problemática 
através da medicina produziu necessariamente uma série de efeitos nos planos político e social. O discurso da Saúde Coletiva, em suma, pretende ser uma leitura crítica desse projeto médico-naturalista, estabelecido historicamente com $o$ advento da sociedade industrial.

Desde que se sublinhe que as relações do sujeito com o seu corpo, com os outros, com as coisas, com as instituições e com as práticas sociais são mediadas pela linguagem, pelos códigos culturais estabelecidos numa tradição histórica e lingüística, torna-se necessário repensar o modelo naturalista da medicina. Introduzem-se aqui, inevitavelmente, considerações acerca dos valores e das relações de força presentes nas relações sociais. A saúde é marcada num corpo que é simbólico, onde está inscrita uma regulação cultural sobre o prazer e a dor, bem como ideais estéticos e religiosos. Destacando assim, nas diversas sociedades, o corpo simbólico, as representações da vida e da morte, do normal e do anormal, as práticas sanitárias não podem silenciar sobre o tecido social, marcado pelas diferenças. O reconhecimento do caráter simbólico do corpo impede sua representação como apenas uma máquina anátomofuncional, constituída por mecanismos bioquímicos e imunológicos.

Os diversos recursos das ciências naturais são irrefutavelmente fundamentais para a investigação e as práticas sanitárias. Mas possuem alcance limitado, pois a problemática da saúde não se restringe ao registro biológico. Por isso, a constituição do discurso teórico da Saúde Coletiva, com a introdução das Ciências Humanas no campo da Saúde, reestrutura as coordenadas desse campo, destacando as dimensões simbólica, ética e política, de forma a relativizar o discurso biológico. As transformações recentes no campo da Epidemiologia, no sentido de demarcar certas regiões de sua racionalidade teórica como Epidemiologia Social, assim como as novas proposições teóricas nos campos da Economia e do Planejamento em Saúde, revelam que esses discursos, há muito existentes, já sofreram transformações no sentido de relativizar a hegemonia atribuída aos saberes biológicos. Na mesma direção, as pesquisas recentes sobre os sistemas humanos de reprodução - nas quais se destacam a ênfase nas concepções de prazer na reprodução biológica, assim como as leituras diferenciadas a respeito da sexualidade humana e da ordenação do corpo sublinham nitidamente a relativização do universalismo naturalista e a conseqüente valorização de modelos teóricos fundados no reconhecimento dos valores e diferenças produzidos no plano simbólico. 
Nessa perspectiva, a noção de saúde coletiva representa uma inflexão decisiva para o conceito de saúde. Um de seus efeitos certamente é o de reestruturar o campo da Saúde Pública, pela ênfase que atribui à dimensão histórica e aos valores investidos nos discursos sobre o normal, o anormal, o patológico, a vida e a morte. De fato, o campo teórico da Saúde Coletiva representa uma ruptura com a concepção de saúde pública, ao negar que os discursos biológicos detenham o monopólio do campo da saúde.

Essa interpretação tem sérias conseqüências para o conceito de saúde e para a gestão política das práticas sanitárias, o que nos leva a sublinhar os pressupostos dessa troca de significantes: em lugar de público, temos o significante coletivo. A troca desses significantes tem como desdobramento um deslocamento da problemática da saúde de seu antigo e exclusivo centro, o Estado, visto como espaço hegemônico para a regulação da vida e da morte na sociedade. Retira-se deste a condição de instância única na gestão do poder e dos valores, e se reconhece o poder instituinte da vida social, nos seus vários planos e instituições. É no descentramento do lugar do Estado e na relativização de seu poder que a problemática do reconhecimento das diferenças no registro epistemológico encontra historicamente seu pólo fundador e suas condições de possibilidade. O limite imposto ao universalismo naturalista e a abertura do campo da saúde para outras leituras possíveis, centradas no reconhecimento das diferenças, é o efeito teórico primordial nesse descentramento.

A multidisciplinaridade é a marca do campo da Saúde Coletiva, já que sua problemática demanda diferentes leituras e permite a construção de diferentes objetos teóricos. Que problemática é esta? Em suma, quais as suas coordenadas e o que delineia suas fronteiras e seu território?

Podemos enunciá-la como relativa às relações entre a natureza e a cultura. Desde o final do século XVIII, estas delineiam o campo da saúde e regulam a produção epistemológica de seus discursos teóricos e o agenciamento das práticas sanitárias. Desde então, a medicina científica se constituiu no seu duplo registro, construindo o campo da saúde como mediação possível para regular as relações complexas entre a natureza e sociedade. Nos dois últimos séculos, novas práticas sanitárias foram inventadas e reinventadas, tendo como objetivo realizar a gestão dessas relações, com base na racionalidade naturalista. Mas o que está em questão no discurso crítico da Saúde Coletiva sobre a Saúde Pública é a explicitação da problemática que se encontra em pauta, para promover uma leitura diferenciada das relações estabelecidas entre natureza e 
sociedade por outros saberes, já que, quando isolado, o discurso naturalista encontra limites para realizar este trabalho.

O campo da Saúde Coletiva é, pois, fundamentalmente multidisciplinar e admite no seu território uma diversidade de objetos e de discursos teóricos, sem reconhecer em relação a eles qualquer perspectiva hierárquica e valorativa. É evidente que os diferentes discursos biológicos têm um lugar fundamental no campo da saúde, o que não deve implicar uma posição hegemônica em relação aos outros.

Por tudo isso, a multidisciplinaridade pretende ser a marca simbólica desta publicação semestral que agora se inicia. Pretendemos reunir trabalhos de pesquisa oriundos de diferentes áreas de conhecimento, dando lugar tanto aos que circulam em campos de objetividade já constituídos, quanto àqueles que promovam a abertura de novos espaços de investigação.

Este número inaugural de Physis pretende realizar o que vimos prometendo ao longo desta apresentação, afirmando os princípios teórico e metodológico que nortearam a leitura aqui apresentada do campo da Saúde Coletiva. A questão da política no campo da Saúde Coletiva se destaca como a problemática que unifica os diversos artigos. A escolha desse eixo se justifica não somente em função de sua importância na conjuntura brasileira, como também em função dos impasses teóricos contemporâneos, que marcam as políticas sociais, o que exige um trabalho de reflexão.

Neste primeiro número, reunimos leituras de diferentes áreas das Ciências Humanas - Sociologia, Ciência Política, História dos Saberes e Filosofia Política - que permitem interpretações dessa problemática mediante diferentes objetos teóricos. Os trabalhos aqui reunidos expressam esses diferentes registros: na perspectiva da Filosofia Política, busca-se realizar a articulação entre as categorias de corpo, norma e saúde; na História da Medicina Social no Brasil, empreende-se uma análise de discurso sobre a instauração do corpo feminino no século XIX; através da Sociologia e da Ciência Política, desenvolvem-se diferentes leituras sobre as recentes políticas de saúde no Brasil, entre as quais se destacam as transformações empreendidas pelo Estado e sua inserção nas políticas sociais; a perspectiva sociológica informa ainda uma análise sobre a apropriação do sangue no Brasil, buscando traçar as vias de sua circulação na sociedade. 


\section{NOTAS}

${ }^{1}$ Publicado originalmente em Physis número 1, volume 1, 1991.

${ }^{2}$ Professor adjunto do Departamento de Políticas e Instituições de Saúde do Instituto de Medicina Social da UERJ.

${ }^{3}$ FOUCAULT, $M$. Naissance de la clinique. Une archéologie du regard médical. Paris: Presses Universitaires de France, 1963.

${ }^{4}$ Ver FOUCAULT M. La politique de la santé au XVIII ${ }^{\text {eme }}$ siècle. In: FOUCAULT M. et al. Les machines à guérir. Paris: Institut de l'environnement, 1976; ROSEN, E. The evolution of social medicine. In: FREEMAN, M. E.; LEVINE, S.; REEDER, L. G. Handbook of Medical Sociology. New York: Prentice-Hall, 1963; ROSEN, G. Da polícia médica à medicina social. Rio de Janeiro: Graal, 1978.

${ }^{5}$ FOUCAULT M. La volonté de savoir. Histoire de la sexualité. V. 1, cap. 5. Paris: Gallimard, 1976.

${ }^{6}$ FOUCAULT M. La naissance de la clinique, Paris: Presses Universitaires de France, 1963. cap. 2 e 3.

${ }^{7}$ Sobre esta questão no campo da AIDS, ver POLLAK, M. Les homosexuels et le SIDA. Sociologie d'une épidémie. Paris: Métailié, 1988. 